\title{
Commentary: Contribution of Interoceptive Information to Emotional Processing: Evidence from Individuals with Spinal Cord Injury
}

\author{
Giuliana Lucci ${ }^{1,2 *}$, Patrizia Sablone ${ }^{2}$ and Erika Nista ${ }^{2}$ \\ ${ }^{1}$ Department of Psychology, University of Rome 'La Sapienza', Rome, Italy, ${ }^{2}$ IRCCS Fondazione Santa Lucia, Rome, Italy
}

Keywords: spinal cord injuries, emotions, mood disorders, interoception, pain

\section{A commentary on}

Contribution of Interoceptive Information to Emotional Processing: Evidence from Individuals with Spinal Cord Injury

by Pistoia, F., Carolei, A., Sacco, S., Conson, M., Pistarini, C., Cazzulani, B., et al. (2015). J. Neurotrauma 32, 1981-1986. doi: 10.1089/neu.2015.3897

We read with interest the study that has been recently published by Pistoia and colleagues on Journal of Neurotrauma (Pistoia et al., 2015). In their work, the authors addressed the longstanding issue concerning the influence of somatic inputs on emotional processing, comparing emotional processing of healthy and complete spinal cord injury (SCI) individuals. Since a complete spinal cord transection causes interruption of the neural flow from the periphery to the brain, SCI represents a useful model for testing the role of somatic inputs in emotional processing. The authors compared performance of healthy and complete SCI individuals in two emotional tasks, i.e., recognition of facial expressions and judgment of emotionally evocative scenes. In summary, Pistoia and co-workers observed difficulties in self-assessing emotionality toward fearful and angry scenes in SCI individuals, despite having normal performance in recognizing emotional faces. The authors explained their results invoking the simulationist theory of emotion recognition.

We have much appreciated this work, primarily because of its contribution in clarifying such a sensitive issue for people affected by SCI. We wish to take the opportunity we were given by reading this paper to highlight some key-points that in our opinion should be taken into account, when investigating how body-brain disconnection affects emotional processing.

For a start, it would be advisable to combine affective stimuli administration with physiological responses recording. As shown by literature on emotions in healthy samples, the subjective perceived stimuli valence and arousal are related to heart rate (Kreibig, 2010), skin conductance (Kreibig, 2010), facial electromyography (Dimberg et al., 2002), and event-related potentials (Hajcak et al., 2010). Neglecting physiological responses prevents from causally and univocally relating altered subjective feelings to body-brain disconnection.

Secondly, in investigating emotional processing in SCI, it must be taken into account the key role of interoception (i.e., the perception of internal bodily signals arising from the organs-e.g., heart, viscera, muscles) in emotional experience and cognition (Seth and Critchley, 2013), as partially done by Pistoia and colleagues. Spinal cord injury can indeed cause several physical sequelae that, by their very nature, could prevent from mapping internal bodily state and then affect emotional processing. We are referring to autonomic dysfunctions (for a review, see Hou and Rabchevsky, 2014), including cardiovascular (Partida et al., 2016) and gastrointestinal (Ebert, 2012) diseases, or autonomic dysreflexia. Autonomic dysreflexia (AD) is a sudden and uncontrolled sympathetic 
response triggered by stimuli below the level of injury. $\mathrm{AD}$ is characterized by elevation of arterial blood pressure, alteration of heart rate and feeling of anxiety (Krassioukov et al., 2009). In any case, the presence and the severity of autonomic dysfunctions could make the pattern of emotional response very different from case to case. Further, in their seminal work, Montoya and Schandry (1994), along with lower interoceptive accuracy and less intense emotionality in SCI than healthy individuals, observed a general positive correlation between interoceptive accuracy and emotional experience, endorsing the central role of interoception in modulating emotional experience.

These data together make advisable to assess interoception in all of its dimensions (Garfinkel et al., 2015) when investigating emotional processing in SCI individuals.

SCI patients frequently suffer from mood disorders, such as depression (Kreuter et al., 1998) and anxiety (Kennedy and Rogers, 2000; Craig et al., 2009) that, if not treated, can persist for two years or more after their onset. A relatively large literature on emotions documented that mood disorders go with emotion processing alterations (Leppänen, 2006; Elliott et al., 2011). Furthermore, psychological diseases get even worse when neuropathic pain, frequently affecting SCI individuals (Finnerup and Jensen, 2004), is present: comorbidity of mood disorders and neuropathic pain is observed in about one-third of SCI individuals (Gustorff et al., 2008). With regard to pain, it is noteworthy its close link with interoception (Tracey and Mantyh,

\section{REFERENCES}

Craig, A., Tran, Y., and Middleton, J. (2009). Psychological morbidity and spinal cord injury: a systematic review. Spinal Cord 47, 108-114. doi: $10.1038 /$ sc. 2008.115

Dimberg, U., Thunberg, M., and Grunedal, S. (2002). Facial reactions to emotional stimuli: automatically controlled emotional responses. Cogn. Emot. 16, 449-471. doi: 10.1080/02699930143000356

Ebert, E. (2012). Gastrointestinal Involvement in Spinal Cord Injury: a Clinical Perspective. J. Gastrointestin. Liver Dis. 21, 75-82. doi: 10.1097/MCG.0b013e3182329d9c

Elliott, R., Zahn, R., Deakin, J. F. W., and Anderson, I. M. (2011). Affective cognition and its disruption in mood disorders. Neuropsychopharmacology 36, 153-182. doi: 10.1038/npp.2010.77

Finnerup, N. B., and Jensen, T. S. (2004). Spinal cord injury pain - mechanisms and treatment. Eur. J. Neurol. 11, 73-82. doi: 10.1046/j.1351-5101.2003.00725.x

Garfinkel, S. N., Seth, A. K., Barrett, A. B., Suzuki, K., and Critcheley, H. D. (2015). Knowing your own heart: distinguishing interoceptive accuracy from interoceptive awareness. Biol. Psychol. 104, 65-74. doi: 10.1016/j.biopsycho.2014.11.004

Gustorff, B., Dorner, T., Likar, R., Grisold, W., Lawrence, K., Schwarz, F., et al. (2008). Prevalence of self-reported neuropathic pain and impact on quality of life: a prospective representative survey. Acta Anaesthesiol. Scand. 52, 132-136. doi: 10.1111/j.1399-6576.2007.01486.x

Hajcak, G., MacNamara, A., and Olvet, D. M. (2010). Event-related potentials, emotion, and emotion regulation: an integrative review. Dev. Neuropsychol. 35, 129-155. doi: 10.1080/87565640903526504

Hou, S., and Rabchevsky, A. G. (2014). Autonomic consequences of spinal cord injury. Compr. Physiol. 4, 1419-1453. doi: 10.1002/cphy.c130045

Kennedy, P., and Rogers, B. A. (2000). Anxiety and depression after spinal cord injury: a longitudinal analysis. Arch. Phys. Med. Rehabil. 81, 932-937. doi: 10.1053/apmr.2000.5580

Krassioukov, A., Warburton, D. E., Teasell, R., and Eng, J. J. (2009). Spinal cord injury rehabilitation evidence research T. A systematic review of the management of autonomic dysreflexia after spinal cord injury. Arch. Phys. Med. Rehabil. 90, 682-695. doi: 10.1016/j.apmr.2008.10.017
2007). Therefore, since the complex scenario mutually involving mood, pain, and interoception in emotionality, it would be helpful assessing the presence and the gravity of both mood disorder and neuropathic pain in investigating emotions in SCI individuals.

Finally, to complete the picture, we must not forget that spinal cord injuries radically affect the life of those suffering from them, causing several losses (i.e., physical, psychological, relational, existential) with whom SCI individuals have to cope. The trauma itself and the coping with the new special life could change subjective emotional framework. Then, to get around this potential confounding variable a control patient group, e.g., patients having breast or prostate removed, could be included when investigating emotions after body-brain disconnection.

We should like to conclude by remarking emotional processing as key issue in the recovery and rehabilitation process of clinical populations, and therefore also for individuals with spinal cord injury, then further works on emotional processing in SCI individuals are necessary and desirable in order to keep trying to improve the quality of their life.

\section{AUTHOR CONTRIBUTIONS}

All authors participated in the preparation and discussion of the commentary.

Kreibig, S. D. (2010). Autonomic nervous system activity in emotion: a review. Biol. Psychol. 84, 394-421. doi: 10.1016/j.biopsycho.2010.03.010

Kreuter, M., Sullivan, M., Dahlöff, A. G., and Siösteen, A. (1998). Partner relationships, functioning, mood and global quality of life in persons with spinal cord injury and traumatic brain injury. Spinal Cord 36, 252-261. doi: 10.1038/sj.sc.3100592

Leppänen, J. M. (2006). Emotional information processing in mood disorders: a review of behavioral and neuroimaging findings. Curr. Opin. Psychiatry 19, 34-39. doi: 10.1097/01.yco.0000191500.46411.00

Montoya, P., and Schandry, R. (1994). Emotional experience and heartbeat perception in patients with spinal cord injury and control subjects. $J$. Psychophysiol. 8, 289-296.

Partida, E., Mironets, E., Hou, S., and Tom, V. J. (2016). Cardiovascular dysfunction following spinal cord injury. Neural Regen. Res. 11, 189-194. doi: 10.4103/1673-5374.177707

Pistoia, F., Carolei, A., Sacco, S., Conson, M., Pistarini, C., Cazzulani, B., et al. (2015). Contribution of interoceptive information to emotional processing: evidence from individuals with spinal cord injury. J. Neurotrauma 32, 1981-1986. doi: 10.1089/neu.2015.3897

Seth, A. K., and Critchley, H. D. (2013). Extending predictive processing to the body: emotion as interoceptive inference. Behav. Brain Sci. 36, 227-228. doi: $10.1017 /$ S0140525X12002270

Tracey, I., and Mantyh, P. W. (2007). The cerebral signature for pain perception and its modulation. Neuron 55, 377-391. doi: 10.1016/j.neuron.2007. 07.012

Conflict of Interest Statement: The authors declare that the research was conducted in the absence of any commercial or financial relationships that could be construed as a potential conflict of interest.

Copyright (c) 2016 Lucci, Sablone and Nista. This is an open-access article distributed under the terms of the Creative Commons Attribution License (CC BY). The use, distribution or reproduction in other forums is permitted, provided the original author(s) or licensor are credited and that the original publication in this journal is cited, in accordance with accepted academic practice. No use, distribution or reproduction is permitted which does not comply with these terms. 